\title{
Revizyon diz artroplastisinde kemik defektlerinin rekonstrüksiyonu
}

\section{Reconstruction of bone defects in revision knee arthroplasty}

\author{
Çetin Işık, Murat Bozkurt \\ Yıldırım Beyazıt Üniversitesi Tıp Fakültesi, Ankara Atatürk Eğitim ve Araştırma Hastanesi, Ortopedi ve Travmatoloji Anabilim Dalı, Ankara
}

\begin{abstract}
Revizyon total diz artroplastisinde kemik defektlerinin rekonstrüksiyonu aşaması, uygulanan implantın sağkalımını etkileyen en önemli basamaklardandır. ilk önce, defekt tam olarak tanımlanmalıdır. Daha sonra, kemik defekti sınıflama sistemleri kullanılarak, defektin tipi belirlenir. Bu amaçla en sık kullanılan sınıflama, Anderson Ortopedik Araştırma Enstitüsü (AORI) kemik defekti sınıflamasıdır. Rekonstrüksiyonda hangi desteğin kullanılacağına da kemik defekti sınıflamasına göre karar verilir. Genel olarak, küçük sınırlı defektler kemik çimentosu ve vida kombinasyonu veya ufalanmış allogreft ile tedavi edilebilirken, daha büyük sınırlanamayan defektlerde, metal blok ve kama destekler, büyük yapısal allogreftler veya yüksek poroziteli konik metafizyel metallere ihtiyaç duyulur. Tüm bu seçeneklerin uygulanamadığı, metafiz ve diyafizer kemiğin ileri derecedeki defektlerinde, tümör rekonstrüksiyon protezleri de son seçenek bir tedavi yöntemi olabilir.
\end{abstract}

Anahtar sözcükler: aşılama, kemik; diz protezi; kemik çimentosu; kemik vidaları
The stage of reconstruction of bone defects in revision total knee arthroplasty is one of the most crucial steps affecting the survival of the implant applied. The defect needs to be fully described first. Then, the type of the defect is identified using bone defect classification systems. The most frequently-used classification for this purpose is the bone defect classification by Anderson Orthopedic Research Institute (AORI). The decision of using a particular type of support in reconstruction is given according to bone defect classification. Small, contained defects are usually treated with a combination of bone cement and screw or with morselized allograft, whereas larger, uncontained defects require metal block and wedge augments, large structural allografts or highly porous metal metaphyseal cones. In severe casesof metaphyseal and diaphyseal bone defects, where none of these options are implemented, the last treatment option may be tumor reconstruction prosthesis.

Key words: grafting, bone; knee prosthesis; bone cements; bone screws

lokalizasyonu, revizyonda kullanılacak desteğin tip ve boyutunu etkileyen başlıca faktördür. ${ }^{[2]}$ Genel olarak, küçük sınırlı defektler kemik çimentosu ve vida kombinasyonu veya ufalanmış allogreft ile tedavi edilebilirken, daha büyük sınırlanamayan defektlerde, metal blok ve kama destekler, büyük yapısal allogreftler veya yüksek poroziteli konik metafizyel metallere ihtiyaç duyulur.

\section{Defekt Sınıflaması}

Kemik kaybının sınıflanmasında; defektin boyutu, lokalizasyonu ve derinliğinin yanında, sağlam bir periferik kemik çerçevenin olup olmaması da göz önünde bulundurulabilir. Cerrahi öncesi veya cerrahi sırasında defektin tanımlanıp, defekt sınıflamasının yapılması; tedavide tercih edeceğimiz rekonstrüksiyon yönteminin

- Illetişim adresi: Dr. Çetin Işık, Yıldırım Beyazıt Üniversitesi Tıp Fakültesi, Ankara Atatürk Eğitim ve Araştırma Hastanesi, Ortopedi ve Travmatoloji Kliniği, 06800 Bilkent, Çankaya, Ankara Tel: 0312 - 2912525 e-posta: cisik@ybu.edu.tr

- Geliștarihi: 8 Nisan 2015 Kabul tarihi: 8 Nisan 2015 
Tablo 1. AORI Kemik Defekti Sınıflaması

\begin{tabular}{ll}
\hline Tip & Özellik \\
\hline Tip I defekt & Sağlam metafizer kemik, stabiliteyi bozmayan küçük femoral veya tibial defektler. \\
Tip II defekt & $\begin{array}{l}\text { Hasarlı metafizer kemik, kansellöz kemik kaybı vardır. Stabiliteyi sağlamak için sıklıkla çimento dolgu, prostetik } \\
\text { destek veya kemik grefti gerektirir. }\end{array}$ \\
Tip III defekt & $\begin{array}{l}\text { Eksik metafızer kemik, femoral kondil veya tibial platonun büyük bir kısmı hasarlıdır. Sıklıkla kollateral bağ veya } \\
\text { patellar tendon ayrılması ile beraberdir. }\end{array}$
\end{tabular}

belirlenmesinde oldukça yararlıdır. Anderson Ortopedik Araştırma Enstitüsü (AORI) Kemik Defekti Sınıflaması, hem tibia, hem de femur kemik defektlerinin sınıflamasında sıklıkla kullanılmaktadır (Tablo 1). ${ }^{[3]}$

\section{KEMIK ÇіMENTOSU VE VIDA}

Kemik çimentosu, defekt rekonstrüksiyonunda kullanılabilen ucuz, basit ve etkili bir seçenektir. Zaten çoğu primer ve revizyon olgusunda tespit amacı ile de kullanıldığından, özellikleri iyi bilinmektedir. Esneme payının düşük olması ve kemik hacmini arttırmaması, çimento kullanımını kısıtlayan en önemli faktörlerdir. Teknik olarak, uygulama öncesi sklerotik kemik yüzeyleri, punktat kanama odakları görülünceye kadar yüksek devirli matkapla debride edilmelidir. Tipik olarak, derinliği 5 mm'nin altında olan, küçük ve sınırlı defektlerde kullanılır. ${ }^{[4]}$ Bazı yazarlar tarafından daha büyük defektlerde de kullanılması savunulmaktadır. Özellikle mediyal tibial platonun, çimento endikasyonunu aşan daha büyük defektlerinde, çimento-vida kombinasyonunun kollapsı engellediği de gösterilmiş ve orta dönem tatmin edici sonuçlar rapor edilmiştir. ${ }^{[5]}$ Büyük defektlerde çimentonun vida ile desteklenmesinin önerilmesi, yapının biyomekanik dayanıklıığını arttırması nedeniyledir. Ancak, bu tip defektler için, özellikle genç ve aktif hastalarda ufalanmış allogreftlerin tercih edilmesi, daha avantajı olabilir.

\section{UFALTILMIŞ OTOGREFT VEYA ALLOGREFT}

Özellikle daha büyük defekti olan genç hastaların revizyonunda, ufaltılmış kansellöz otogreft veya allogreftler başarı ile kullanılmaktadır. ${ }^{[6,7]}$ Biyolojik olarak, daha az bir oranda da olsa, ufaltılmış kansellöz allogreftlerin konulduğu bölgedeki kemik ile birleşmesi, kansellöz otogreft ile benzer görülmektedir. Greftin konulduğu yerin kanlanmasının iyi olması, greft inkorporasyonunu arttıracaktır. En önemli avantajları, kemik hacminin yeniden kazanılmasına olanak vermeleridir (Şekil 1). Sınırları belirgin olmayan defektler için tek başına kullanılamazlar. Bazı yazarlar, yapısal allogreft
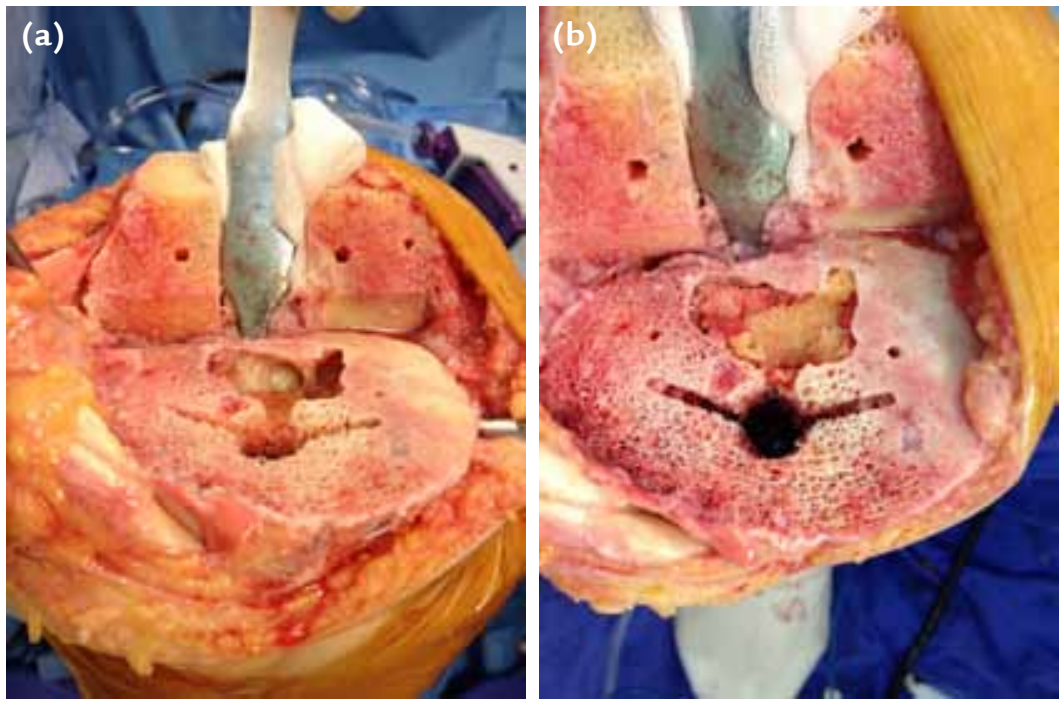

Şekil 1. a, b. Duvarları sağlam, sınırlı tibial defekt (a). Aynı defekt kansellöz otogreft ile doldurulmuş (b). 
veya metalik destek gerektirebilecek geniş defektlerde de ufaltılmış greftlerin sıkıştırılması tekniğini kullanmışlar ve yeterli sonuç bildirmişlerdir. ${ }^{[7,8]}$ Örneğin; tibial metafizer bir defektte, bir deneme sap (stem) uygun dizilim için tibial kanalın içine yerleştirilir, kemik grefti sapın etrafına sıkıştırılır ve ardından kemik grefti defekti doldurduğunda deneme sap çıkarılır. Böylece, greft istenilen yere ve sıkıştırılarak istenilen şekilde yerleştirilmiş olur. Eğer defektin sınırları belirgin değil ise, korteks anatomisinin restorasyonu için metal mesh'ler kullanılabilir. Metal mesh, kemiğin normal konturlarına göre şekillendirilir ve küçük kortikal vidalar ile yerine tutturulur. Ufaltılmış allogreftler, komponent sapının çevresine ve metal mesh içine doldurulur ve sıkıştırılır.

\section{YAPISAL ALLOGREFTLER}

Yapısal allogreftler; duvar bütünlüğü bozulmuş, sınırları belirgin olmayan, geniş, metal blok destekler ile restore edilemeyecek ve derinliği 15 mm'nin üzerindeki kemik defektler için endikedir. Özellikle genç hastalarda, kemik rekonstrüksiyonuna olanak tanıyan yapısal allogreftlerin; greft rezorbsiyonu, çökme ve yerleştirildiği yerdeki kemiğe kaynamama gibi dezavantajları mevcuttur. Kemik defektinin rekonstrüksiyonunda yapısal allogreft tercih edilecekse; hastanın fizyolojik yaşı, kemik kalitesi, aktivite düzeyi ve genel sağlık durumu göz önünde bulundurulmalıdır. Femoral kondillerin veya tibial platoların birinin ya da her ikisinin metal destekler ile rekonstrüksiyonu mümkün değilse, yapısal allogreftler kullanılmalıdır (Şekil 2).

Geniş defekt, femurda tek bir femoral kondili tutuyorsa, tibiada ise izole mediyal veya lateral tibial platoda yer alıyorsa; rekonstrüksiyonda femur başı allogrefti tercih edilebilir. Cerrahi teknikte, bir hemisferik asetabular reamer kullanılarak, kemik defekti femur başının sığacağı miktarda genişletilir. Aynı boyda ters hemisferik reamer ile, femur başı allogreftindeki kıkırdak debris temizlenir. Femur başı kemik defektine oturtulur ve iki adet vida ile fikse edilir. Fikse edilen başa, yüksek devirli burr ile istenilen şekil verdirilebilir. Böylece, kullanılan allogrefte, konulduğu bölgeye özgü anatomik şekil verdirilebilir veya birlikte kullanılacağı implanta uyumlu hale getirilebilir.

Her iki femoral kondil ve distal femoral metafizi tutan, kollateral bağların tutunduğu noktaların korunduğu büyük osteolitik defektlerde, distal femoral allogreft kullanımı endikedir. Bu teknik ile, kollateral bağların tutunduğu noktalar korunurken, kemik hacminin yeniden kazanılmasına olanak sağlanır. Hasarlı kemiğin büyük masif bir allogreft ile replase edilmesi, etkisi kanıtlanmış bir tedavi seçeneğidir. ${ }^{[9]}$ Distal femoral allogreftin gerekli olabileceği olgularda, femurun ve allogreftin cerrahi öncesi boyutlandırılması önemlidir.
Femur ile allogreftin radyografilerinin karşılaştırılması (mümkünse ameliyat edilmeyen karşı dizle mukayese edilmelidir), uyumsuzluk olasılığını azaltır. Allogreft, femur ile (kemik içinde kemik) iç içe olacak şekilde monte edilir. Yani, distal femurda sağlam kortikal kabuk varsa, daha küçük bir distal femoral allogreft, ana kortikal kabuk içinde stabilize edilebilir. Allogreftin sağlam bir şekilde yerleştirilmesi çok önemlidir.

Yapısal allogreft kullanılan masif tibial defektli 46 revizyon olgusunda, ortalama 95 aylık takip sonucunda dört yetmezlik bildirilmiş, greft çökmesi ve grefte bağlı aseptik gevşeme ile hiç karşılaşılmadığı rapor edilmiştir. $^{[10]}$ Revizyonda yapısal allogreftlerin kullanıldığı 52 olguluk başka bir ileriye dönük çalışmada, ortalama 97 aylık takip sonunda \%75 oranında başarı, 13 olguda ise başarısızlık bildirilmiştir. Beş dizde greft rezorbsiyonu ve implant gevşemesi, iki dizde de greft ile alıcı kemik arasında kaynamama gözlenmiş, allogreftlerin on yıllık sağkalımının \%72 olduğu ifade edilmiştir. ${ }^{[11]}$ Mayo Klinik kaynaklı yapısal allogreftlerin kullanıldığı 65 olguluk başka bir geriye dönük çalışmada, on yıllık sağkalım \%76 olarak belirtilmiştir.

\section{METAL DESTEKLER}

\section{Metal Blok ve Kamalar}

Bunlar, küçük ve orta büyüklükteki segmental tibial ve femoral defektlerde endikedir. Çok yönlü kullanılmaları, etkili ve teknik olarak kolaylıkla uygulanabilmeleri, metal blokların avantajlarıdır. Ayrıca osseoentegrasyon gelişimi gerektirmezler. Bilhassa yaşlı ve daha az aktif hastalarda yararlıdırlar. En belirgin dezavantajları, kemik stoğun restore edilememesidir. Çoğu revizyon total diz sisteminin, eklem hattı ve diz balansının restorasyonunu kolaylaştıran çok sayıda boyut ve şekile sahip metal destekleri mevcuttur (Şekil 3).

Metal kama ve blok tekniklerinin hepsinde amaç; defektin sınırlarını düzgün hale getirmek, sağlıklı bir korteks elde etmek ve iyi fikse edilmiş intramedüller bir sapın desteklediği komponenti yerleştirmektir. İzole metal blok ve kamaların kullanıldığı esas endikasyon, Tip II kemik defektleridir. ${ }^{[12]}$ Belirgin kemik harabiyeti olan Tip III defektlerde, genellikle büyük yapısal allogreftler ile kombine edilerek de kullanılabilirler. 30 mm'ye kadar olan defektleri doldurmak için, çimentoyla güçlendirilmiş desteklerin kullanılmasına yönelik çalışmalar da mevcuttur. ${ }^{[13]}$

Teknik olarak, özellikle tibial metafizyel kemiğin üzerinden taşan metal destek, kollateral bağ veya yumuşak dokuyu tahriş edebilir. Bu durumda, tibial komponentin küçültülmesi gerekebilir. Mediyal ve lateral blok veya kama metal desteklerin eşzamanlı kullanımı veya tam blok, tam kama destek kullanımı; eklem hattının 

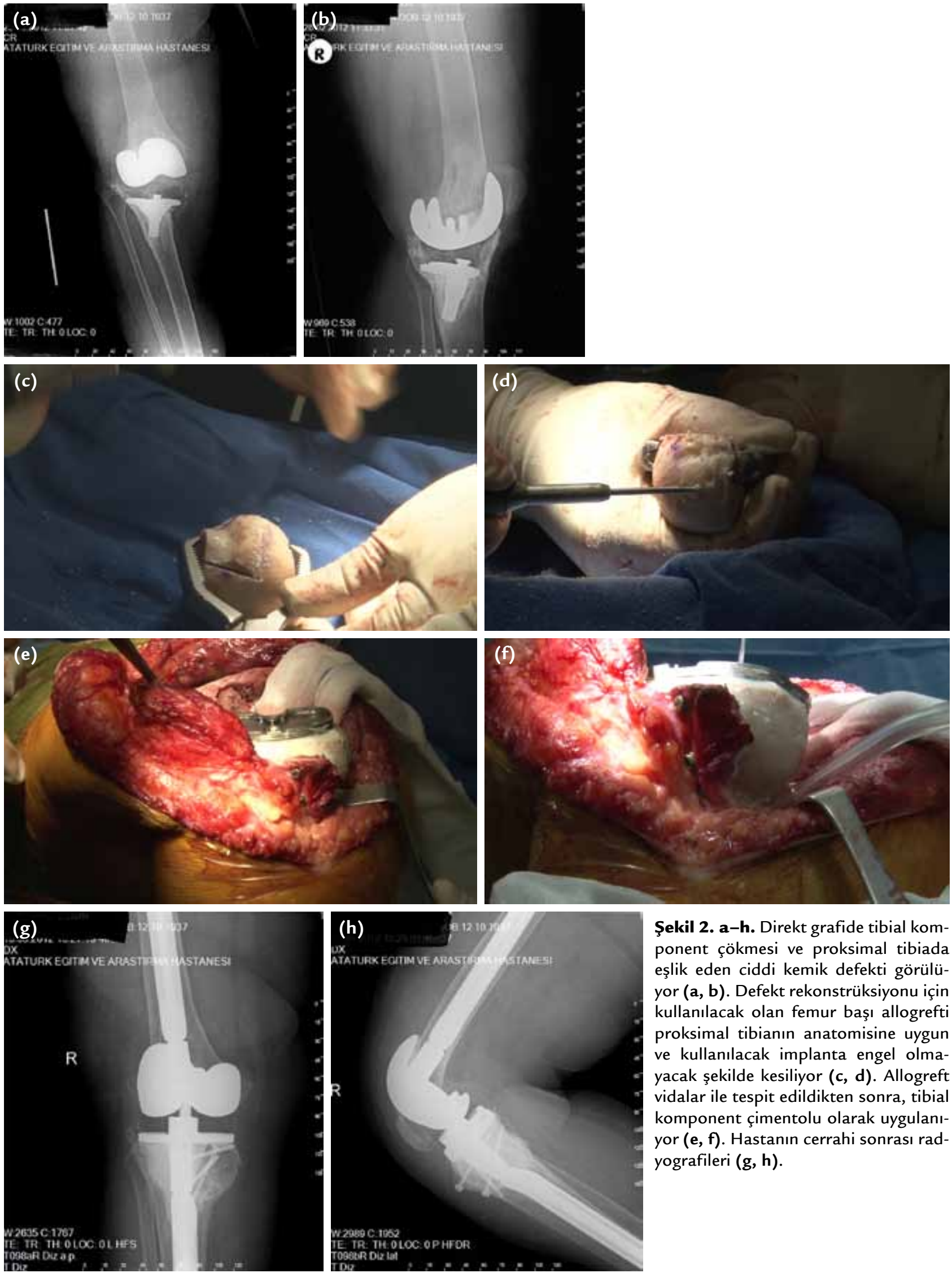

Şekil 2. a-h. Direkt grafide tibial komponent çökmesi ve proksimal tibiada eşlik eden ciddi kemik defekti görülüyor $(\mathbf{a}, \mathbf{b})$. Defekt rekonstrüksiyonu için kullanılacak olan femur başı allogrefti proksimal tibianın anatomisine uygun ve kullanılacak implanta engel olmayacak şekilde kesiliyor (c, d). Allogreft vidalar ile tespit edildikten sonra, tibial komponent çimentolu olarak uygulanıyor $(\mathbf{e}, \mathbf{f})$. Hastanın cerrahi sonrası radyografileri $(g, h)$. 

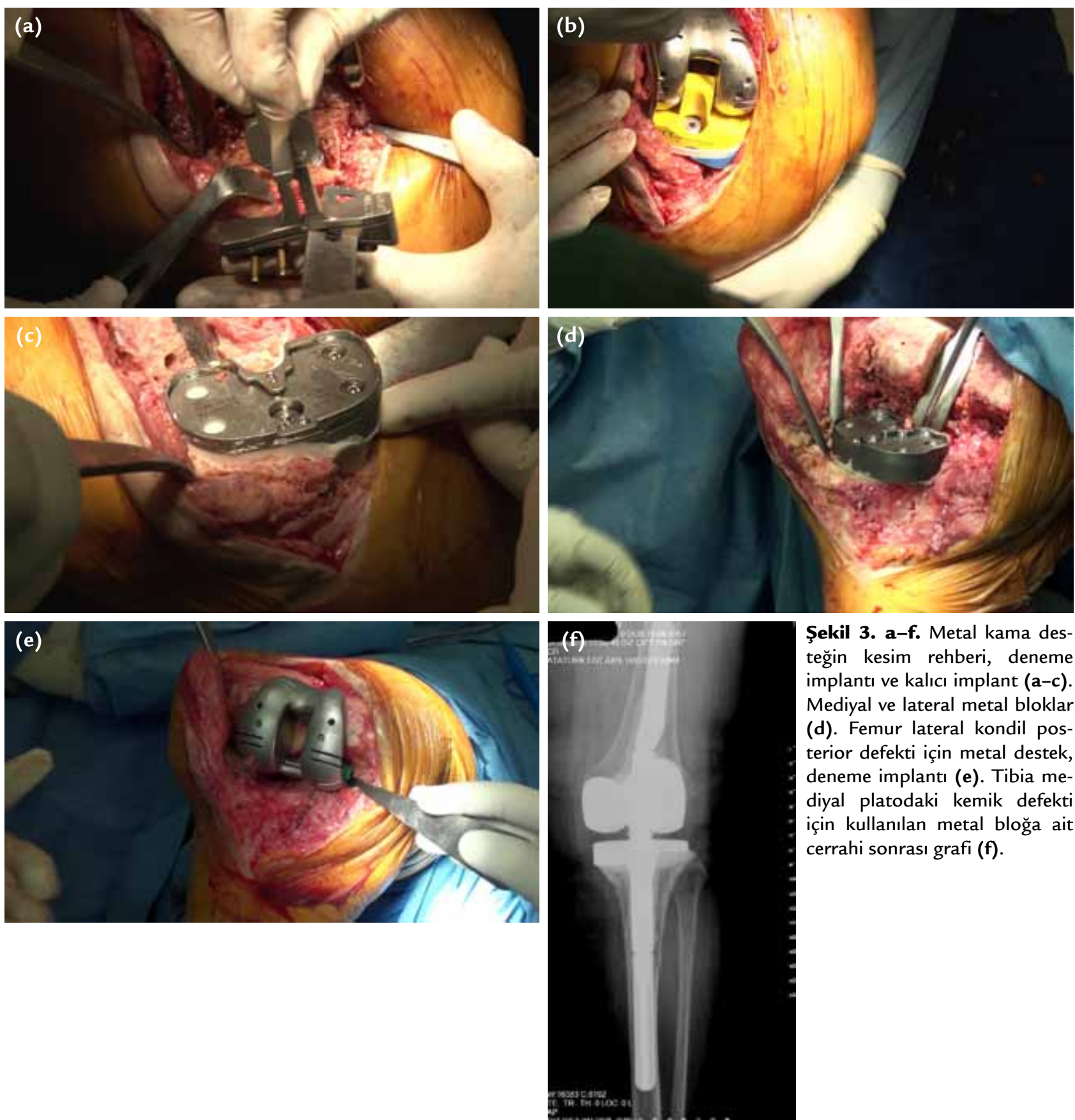

Şekil 3. a-f. Metal kama desteğin kesim rehberi, deneme implantı ve kalıcı implant (a-c). Mediyal ve lateral metal bloklar (d). Femur lateral kondil posterior defekti için metal destek, deneme implantı (e). Tibia mediyal platodaki kemik defekti için kullanılan metal bloğa ait cerrahi sonrası grafi (f).

muhtemel elevasyonuna yol açabilir. Eklem hattı restore edildiyse, mediyal ve lateral destekler ile, daha ince bir insert kullanılarak, polietilen üzerindeki varus/valgus momenti azaltılmaya çalışılabilir.

Değişik çalışmalarda, metal destekler ile yapılan revizyon diz artroplastilerinde başarılı orta dönem sonuçlar rapor edilmiştir. 2004 yılında yapılan bir çalışmada, metal destek kullanılan Tip II defektli 102 revizyon diz artroplastisinde, 11 yıl sonunda ortalama sağkalım \%92 olarak bildirilmiştir. Metal destek etrafinda \%14 oranında progresif olmayan radyolusen hat gözlenmiş, fakat implant yetmezliğinde artış ile ilişkilendirilememiştir. ${ }^{[14]}$

Metal destekli tibial komponentlerin kullanımı ile ilgili yapılmış ilk çalışmalardan birinde, Brand ve arkadaşları, ortalama 37 ay takip ettikleri 22 olguda herhangi bir başarısızıık olmadığını ve ilerleme göstermeyen radyolusen çizgi insidansının \%27 olduğunu raporlamıştır. ${ }^{[15]}$ 


\section{Poroz Metafizyel Konik Destek ve Serbest Trabeküler Metal Destekler}

Yüksek poroziteli konik metafizyel metal destekler, yakın dönemde geliştirilmiş ve geniş tibial ve femoral defektlerde kullanılmaktadır. Kullanılmaları ile, kaynamama ve yapısal allogreftlerde görülen greft rezorbsiyonu gibi komplikasyonların önlenmesi amaçlanmaktadır. Yüksek poroziteli metaller, özellikle de ülkemizde kullanılamayan poroz tantalum, geleneksel materyallerin ötesinde değişik avantajlar sunan biyomateryallerdir. Bunların avantajları; düşük sertlik, yüksek porozite ve yüksek sürtünme katsayısıdır. Biyolojik birleşme ve mekanik destek sağlama yanında, revizyonda karşılaşılan değişik şekilli ciddi kemik kayıplarını restore edebilme niyeti ile tasarlanmışlardır (Şekil 4). Revizyon total diz artroplastisinde, geniş tibial defektlerin rekonstrüksiyonunda, bu implantların kullanımını destekleyen kısa dönem kanıtlar bulunmaktadır. ${ }^{[16-18]}$

Tibiada metafizyel konik destekler uygulanırken, ilk önce proksimal tibial kesi yapılıp uzatma için yer açılır. Daha sonra deneme konik destek yerleştirilir ve uygun rotasyonda anterior tibia işaretlenir. Uygun büyüklükteki tibial komponent, konik destek ve uzatma sap birleştirilir. Tibial komponent ve destek arasında görülebilecek rotasyonel uyumsuzluk kontrol edilerek, tibial komponentin de rotasyonu belirlenir. Tibial konik destek, revizyon tibial komponentin üzerine sıkıştırılır. Komponent konulurken ve sıkıştırılırken metafizyel konik desteğin büyüme iç yüzeylerine çimento bulaşmamasına dikkat edilmelidir. Birçok konik desteğin gözenekli yüzey kaplaması kemik büyümesine olanak sağladığından, çimento sadece monte edilen yüzeye
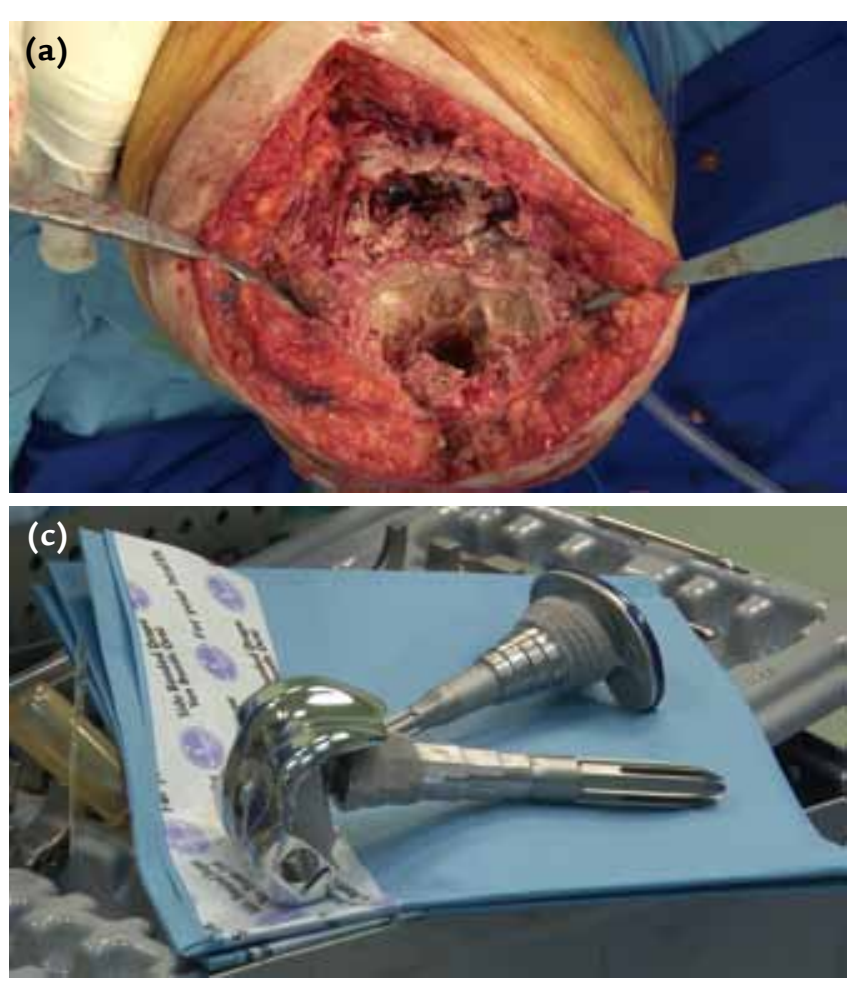

(f)

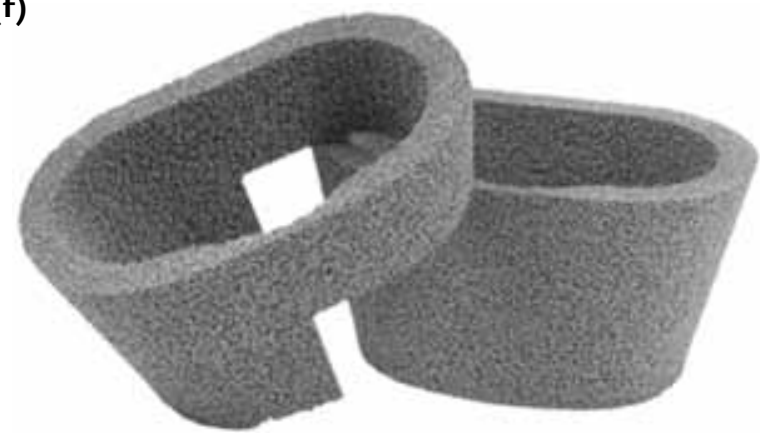

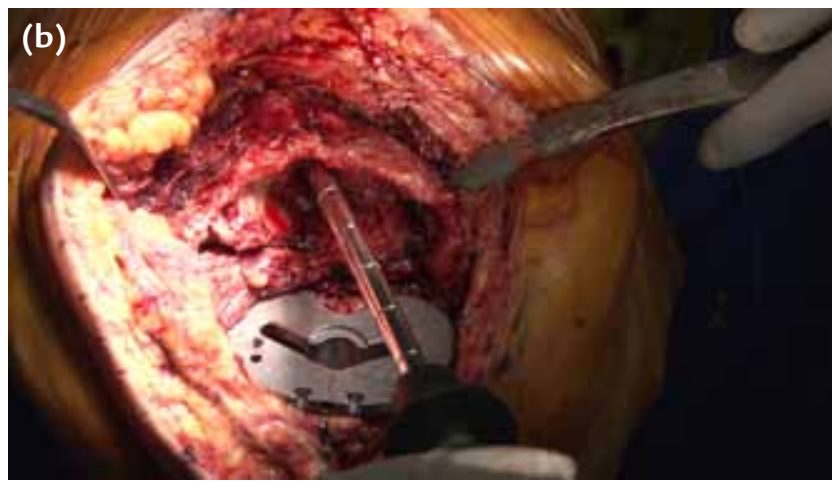

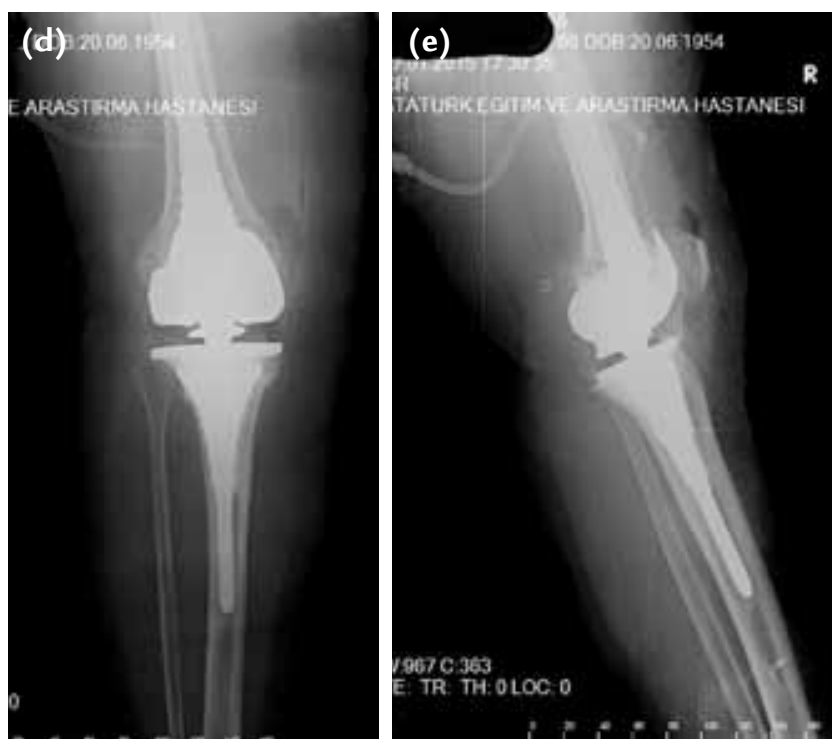

Şekil 4. a-f. Tibia ve femurda geniş kemik defekti, cerrahi sırasında görüntü (a, b). Hem tibia hem de femurdaki defekt rekonstrüksiyonu için tercih edilen poroz metafizyel konik destek (c). Hastanın cerrahi sonrası radyografileri (d, e). Ülkemizde kullanılamayan, serbest trabeküler metal destek örneği (f). 
uygulanır. Bu sayede, konik destek ve kemik arasında doğrudan kemik teması sağlanır.

Öte yandan, serbest trabeküler konik destekler uygulanırken, ilk önce defekte en çok uyan trabeküler metal destek seçilir ve metal desteğin yerine sımsıkı oturabilmesi için ortamda bulunan küçük kemik parçacıkları yüksek devirli burr kullanılarak temizlenir; daha sonra destek yerine monte edilir. Metafizyel defektin destek ile tam doldurulması şart değildir. Desteğin, kendisini çevreleyen kemiğe tamamen temas etmediği durumlarda, aradaki boşluğu doldurmak için ezilmiş kansellöz allogreft ile demineralize kemik matriksi kullanılabilir. Tibial komponentin sapı, trabeküler metalin içinden geçecek şekilde tibial diyafizin içine yerleştirilir. Tibial sapın proksimal kısmı ve tibial komponent, trabeküler metal desteğe çimento ile yapıştırılır. Sapın geri kalan kısmı ise ya tibia diyafizine press-fit geçirilir ya da ameliyat öncesi plana göre çimentolanır. Saplı implantların kullanımı, ekleme binen yükün eşit oranlarda dağııımını sağlar. Kemik kaybı olan revizyon hastalarında, hemen her zaman kullanılması gerekir.

Bu metal desteklerin endikasyonları; geniş, duvarları sağlam (AORI Tip IIB) defektler ile sınırları belirgin olmayan (AORI Tip III) defektlerdir. Bu yönden, yapısal allogreftler ile endikasyonları benzerdir. Defekt boyutu, blok ve kamalar ile rekonstrükte edilemeyecek kadar geniştir. Cerrahın, özellikle genç hastalar söz konusu ise, yeterli kortikal duvar desteği olan sınırlı defektlerde greft sıkıştırılması tekniğinin daha uygun olabileceğini aklında tutması gerekir. Yine, genç hastaların geniş tibial veya femoral defektlerinin rekonstrüksiyonlarında yapısal allogreftlerin kullanılması, gelecekte yapılacak revizyon cerrahilerinde kemik stoğunun yeniden oluşturulması açısından daha uygun bir yaklaşım olabilir. Dahası, yetersiz kemik desteği veya düşük osseoentegrasyon potansiyeli olan hastalarda, özel sipariş protezler veya tümör rezeksiyon protezleri ile rekonstrüksiyon daha uygun bir seçenek olabilir. Poroz metallerin kullanım endikasyonu için en yaygın tibial senaryo; duvar bütünlüğü bozulmuş mediyal tibial platodaki kemik defekt ve yapısal destek sağlayabilen, kısmen veya tamamen sağlam kalmış lateral tibial platodur. En yaygın femoral senaryo ise; minimal kortikal duvar desteği sağlayan, mediyal ve lateral femoral kondilde aşırı kansellöz kemik kaybı olmasıdır.

Meneghini ve arkadaşları, iki yıl izledikleri ve tantalum metafizyel destek kullandıkları 15 revizyon olgusunda, osseoentegrasyonun sağlandığı, gevşeme veya migrasyona ait bulguya ise rastlanmadığını bildirmişlerdir. ${ }^{[16]}$

Long ve Scuderi, geniş tibial defekt için metafizyel tantalum kullandıkları 15 revizyon olgusunu içeren geriye dönük çalışmalarında, aseptik gevşeme ve mekanik yetmezlik ile karşılaşmadıklarını, kısa dönem takipte de, tüm hastalarda iyi sonuç elde ettiklerini bildirmişlerdir. ${ }^{[17]}$

Trabeküler metal ile elde edilen kısa dönem sonuçlar; benzer zaman aralığındaki yapısal allogreft, geniş modüler metal destek ve özel sipariş protezler ile eşdeğer görülmektedir. İleri klinik ve radyolojik takipler, yüksek poroziteli bu desteklerin uzun dönem dayanıklılığını anlamamızı sağlayacaktır.

\section{TÜMÖR REKONSTRÜKSIYON PROTEZI}

Metafiz ve diyafizer kemiğin aşırı kaybında, ekstremitenin kurtarılması için tasarlanmış modüler implantlar, rekonstrüksiyon için tek seçenek olabilir. Bu seçenek, kemik kaybının otogreft, allogreft veya metalik modüler destekler ile rekonstrüksiyonunun yapılamadığı durumlar için geçerlidir. ${ }^{[19]}$ Yük taşıyabilecek sağlamlıkta, canlı kemik dokuya ulaşabilmek için kemiğin zayıf uçları kesilir. Uygun ekstremite uzunluğu, yumuşak doku gerginliği ve implant rotasyonunu yeniden oluşturulur. Doğru rotasyon ve uzunluk tespit edildiği zaman, implantlar çimentolu veya çimentosuz olarak yerleştirilir.

\section{KAYNAKLAR}

1. Saleh KJ, Rand JA, McQueen DA. Current status of revision total knee replacements: how do we assess results? J Bone Joint Surg Am 2003;85-A Suppl:S18-20.

2. Engh GA, Ammeen DJ. Bone loss with revision total knee arthroplasty: defect classification and alternatives for reconstruction. Instr Course Lect 1999;48:167-75.

3. Engh GA. Bone defect classification. In: Engh GA, Rorabeck $\mathrm{CH}$, editors. Revision total knee arthroplasty. Baltimore, Md, USA: Lippincott Williams \& Wilkins; 1997. p.63-120.

4. Aleto TJ, Berend ME, Ritter MA, Faris PM, Meneghini RM. Early failure of unicompartmental knee arthroplasty leading to revision. J Arthroplasty 2008;23(2):159-63. CrossRef

5. Ritter MA, Harty LD. Medial screws and cement: a possible mechanical augmentation in total knee arthroplasty. J Arthroplasty 2004;19(5):587-9.

6. Bradley GW. Revision total knee arthroplasty by impaction bone grafting. Clin Orthop Relat Res 2000;(371):113-8.

7. Lonner JH, Lotke PA, Kim J, Nelson C. Impaction grafting and wire mesh for uncontained defects in revision knee arthroplasty. Clin Orthop Relat Res 2002;(404):145-51.

8. Lotke PA, Carolan GF, Puri N. Impaction grafting for bone defects in revision total knee arthroplasty. Clin Orthop Relat Res 2006;446:99-103.

9. Bezwada HP, Shah AR, Zambito K, Cerynik DL, Johanson NA. Distal femoral allograft reconstruction for massive osteolytic bone loss in revision total knee arthroplasty. J Arthroplasty 2006;21(2):242-8.

10. Engh GA, Ammeen DJ. Use of structural allograft in revision total knee arthroplasty in knees with severe tibial bone loss. J Bone Joint Surg Am 2007;89(12):2640-7. 
11. Clatworthy MG, Ballance J, Brick GW, Chandler HP, Gross $\mathrm{AE}$. The use of structural allograft for uncontained defects in revision total knee arthroplasty: a minimum five-year review. J Bone Joint Surg Am 2001;83-A(3):404-11.

12. Engh GA, Ammeen DJ. Classification and preoperative radiographic evaluation: knee. Orthop Clin North Am 1998;29(2):205-17.

13. Hockman DE, Ammeen D, Engh GA. Augments and allografts in revision total knee arthroplasty: usage and outcome using one modular revision prosthesis. J Arthroplasty 2005;20(1):35-41.

14. Patel JV, Masonis JL, Guerin J, Bourne RB, Rorabeck CH. The fate of augments to treat type-2 bone defects in revision knee arthroplasty. J Bone Joint Surg Br 2004;86(2):195-9.

15. Brand MG, Daley RJ, Ewald FC, Scott RD. Tibial tray augmentation with modular metal wedges for tibial bone stock deficiency. Clin Orthop Relat Res 1989;(248):71-9.
16. Meneghini RM, Lewallen DG, Hanssen AD. Use of porous tantalum metaphyseal cones for severe tibial bone loss during revision total knee replacement. J Bone Joint Surg Am 2008;90(1):78-84. CrossRef

17. Long WJ, Scuderi GR. Porous tantalum cones for large metaphyseal tibial defects in revision total knee arthroplasty: a minimum 2-year follow-up. J Arthroplasty 2009;24(7):108692. CrossRef

18. Radnay CS, Scuderi GR. Management of bone loss: augments, cones, offset stems. Clin Orthop Relat Res 2006;446:83-92.

19. Harrison RJ Jr, Thacker MM, Pitcher JD, Temple HT, Scully SP. Distal femur replacement is useful in complex total knee arthroplasty revisions. Clin Orthop Relat Res 2006;446:113-20. 